\title{
Association Between Patients' Immunoglobulin E Levels and Difficulty Eradicating Helicobacter pylori
}

\author{
Kayoko Ozeki iD ${ }^{1,2}$ \\ Takahisa Furuta ${ }^{3}$ \\ Toshiyuki Ojimal \\ 'Department of Community Health and \\ Preventive Medicine, Hamamatsu \\ University School of Medicine, \\ Hamamatsu, Shizuoka, Japan; \\ ${ }^{2}$ Department of Pharmaceutical Health \\ Care and Science, Aichi Gakuin \\ University, Nagoya, Aichi, Japan; ${ }^{3}$ Center \\ for Clinical Research, Hamamatsu \\ University School of Medicine, \\ Hamamatsu, Shizuoka, Japan
}

Background: Helicobacter pylori is a cause of gastric cancer, and thus the eradication of this bacterium is very important. The success rate of primary eradication has been dramatically increased by the introduction of potassium-competitive acid blockers. However, H. pylori cannot be eradicated in all patients, and the contributing factors need to be clarified. Aim: Because allergy status may be a factor and considering research linking hay fever with eradication failure, the purpose of this study was to examine blood immunoglobulin E levels as a contributing factor in patients who were unable to eradicate $H$. pylori in a single eradication treatment and who underwent multiple eradication attempts.

Methods: Questionnaire data were collected from 250 patients who visited the Department of Gastroenterology, Hamamatsu University School of Medicine, for H. pylori eradication. In addition, non-specific IgE levels in the blood were measured and analyzed with one-way analysis of variance. Multinomial logistic regression analysis was performed to examine the association between the number of eradication attempts and the $\operatorname{IgE}$ level $(<500 \mathrm{vs} \geq 500 \mathrm{IU} / \mathrm{mL})$.

Results: The mean IgE values were 188.4, 211.9, and $744.0 \mathrm{IU} / \mathrm{mL}$ in patients with one, two, and three or more eradication attempts, respectively $(\mathrm{P}<0.05)$. The results of multinomial logistic regression analysis showed that attempting eradication three or more times was significantly associated with high levels of IgE, even after consideration of antibiotic sensitivity.

Conclusion: H. pylori eradication was less likely in patients with high IgE. It is thus necessary to study the appropriate regimen for patients with high $\operatorname{IgE}$ levels.

Keywords: Helicobacter pylori, multiple eradication, antibiotic sensitivity

\section{Introduction}

Previous research has shown that Helicobacter pylori causes gastric ulcers and gastric cancer ${ }^{1-4}$ and that eradication of $H$. pylori can reduce the risk of gastric cancer. $^{5,6}$ Therefore, successful eradication is vital.

In Japan, the eradication rate with the use of amoxicillin/clarithromycin/protonpump inhibitor combination therapy as first-line therapy is reported to be $60 \%$ to $70 \%{ }^{7,8}$ In 2015 , the proton-pump inhibitor was replaced with vonoprazan, which is a potassium-competitive acid blocker (P-CAB), and this dramatically increased the success rate of primary eradication to about $90 \%{ }^{9}$ However, eradication is not possible in some people, and clarification of the contributing factors is important. We previously reported that eradication failure is associated with hay fever ${ }^{10}$ and with alcohol consumption in female patients. ${ }^{11}$
Correspondence: Kayoko Ozeki Department of Community Health and Preventive Medicine, Hamamatsu University School of Medicine, I-20-I

Handayama, Higashiku, Hamamatsu, Shizuoka, 43I-3192, Japan

Tel +8I 534352333

Fax +8I 53435234 I

Email kozeki@dpc.agu.ac.jp 
In the present study, we examined the blood IgE levels of patients who were unable to eradicate $H$. pylori despite multiple attempts, considering the possibility that patients' physical constitution might be a contributing factor. Although there have been several analyses of the blood parameters of patients with $H$. pylori infection, few studies have described the relationship between patients' blood parameters and eradication.

Therefore, the purpose of this study was to examine blood IgE levels as a contributing factor in patients who were unable to eradicate $H$. pylori in a single eradication treatment and who underwent multiple eradication attempts. We focused on IgE levels, which are caused by patient's allergy status, because we previously found that H. pylori eradication was less likely in patients with hay fever. In particular, we sought to clarify the relationship between the difficulty of eradication and the raw IgE values, as well as the relationship with high and low IgE levels. We also took into account antibiotic sensitivity.

\section{Materials and Methods}

Completed questionnaires and blood test data were obtained from 250 patients who visited the Department of Gastroenterology of Hamamatsu University School of Medicine for H. pylori eradication between April 2017 and December 2020. Patient consent was obtained after written explanation of the study aims. The questionnaire items included sex, age, alcohol consumption, smoking, previous eradication experience, and number of previous eradication attempts. In addition, non-specific IgE levels in the blood were measured. The test method applied was fluorescence enzyme immunoassay (FEIA), a type of enzyme immunoassay in which an antigen-antibody reaction is achieved using antigens or antibodies labeled with enzymes on labeled substances and the fluorescence intensity of the fluorescent substrate is measured. The exclusion criterion was no response to the required items.

Because the patients came to the university hospital for eradication, many of them had experienced failed eradication at least once at their general practitioners or at other hospitals. Amoxicillin, clarithromycin, and vonoprazan were used for primary eradication, whereas amoxicillin, metronidazole, and vonoprazan were used for secondary eradication. After the third eradication attempt, the choice of treatment was left largely to the physicians' discretion. In many cases, sitafloxacin and minocycline were used instead of amoxicillin.
We performed a simple tabulation of the attributes of 250 patients who visited the Department of Gastroenterology, Hamamatsu University School of Medicine, for H. pylori eradication, including sex, age, and other characteristics (Table 1). Next, 26 patients with autoimmune gastritis who did not have H. pylori infection were excluded. Furthermore, patients who had never undergone eradication were excluded, and 151 patients who had undergone eradication at least once were selected. We divided the patients into three groups (one, two, and three or more eradication

Table I Patients' Demographic Characteristics

\begin{tabular}{|c|c|c|}
\hline Characteristic & $\mathbf{n}$ & $\%$ \\
\hline \multicolumn{3}{|l|}{ Sex } \\
\hline Male & 109 & 43.6 \\
\hline Female & $|4|$ & 56.4 \\
\hline \multicolumn{3}{|l|}{ Age, years } \\
\hline$\leq 30$ & 7 & 2.8 \\
\hline $31-40$ & 33 & 13.2 \\
\hline $4 I-50$ & 30 & 12.0 \\
\hline $51-60$ & 52 & 20.8 \\
\hline $61-70$ & 85 & 34.0 \\
\hline $7 I-80$ & 38 & 15.2 \\
\hline$\geq 81$ & 5 & 2.0 \\
\hline \multicolumn{3}{|l|}{ Smoking status } \\
\hline Smoking $(+)$ & 23 & 9.2 \\
\hline Smoking $(-)$ & 211 & 84.4 \\
\hline Non-response & 16 & 6.4 \\
\hline \multicolumn{3}{|l|}{ Drinking status } \\
\hline Drinking $(+)$ & 127 & 50.8 \\
\hline Drinking (-) & 102 & 40.8 \\
\hline Non-response & 21 & 8.4 \\
\hline \multicolumn{3}{|l|}{ Inspection of $H$. pylori } \\
\hline Inspection (+) & 195 & 78.0 \\
\hline Inspection (-) & 33 & 13.2 \\
\hline Unknown & I & 0.4 \\
\hline Non-response & 21 & 8.4 \\
\hline \multicolumn{3}{|l|}{ Eradication of $H$. pylori } \\
\hline Eradication $(+)$ & 153 & 61.2 \\
\hline Eradication $(-)$ & 70 & 28.0 \\
\hline Unknown & 1 & 0.4 \\
\hline Non-response & 26 & 10.4 \\
\hline \multicolumn{3}{|l|}{ Number of $H$. pylori eradication treatments } \\
\hline One & 44 & 17.6 \\
\hline Two & 81 & 32.4 \\
\hline Three & 16 & 6.4 \\
\hline Four & 10 & 4.0 \\
\hline Patients with autoimmune gastritis (not $H$. pylori infection) & 26 & 10.4 \\
\hline
\end{tabular}


attempts), assessed the mean values of non-specific $\operatorname{IgE}$ levels, and performed a one-way analysis of variance (Table 2), which was the exclusion criterion.

In addition, regarding the eradication difficulty, multinomial logistic regression analysis was performed to examine the association between the number of eradication attempts and the level of $\operatorname{IgE}$ (dichotomized as $<500$ and $\geq 500 \mathrm{IU} / \mathrm{mL}$ ) (Table 3 ).

In model 1, IgE level (with low as reference) was used as the independent variable, and the number of eradication attempts (with one as reference) was used as the dependent variable. In model 2, clarithromycin sensitivity was added as a covariate. We examined the susceptibility to clarithromycin by blood tests. The susceptibility values were < $0.015,0.03,0.06,2,4,8,16,32$, and $64 \mu \mathrm{g} / \mathrm{mL}$. The threshold for clarithromycin susceptibility was set at 1 $\mu \mathrm{g} / \mathrm{mL}$ using the criteria recommended by the American Board of Clinical and Laboratory Standards Institute (CLSI) and the Japanese Society for Chemotherapy. In model 3, clarithromycin susceptibility, sex, age, presence of alcohol consumption, and smoking were added as covariates for analysis.

Statistical analysis was performed using SPSS version 24. A P-value $<0.05$ was considered statistically significant.

\section{Results}

The patients' demographic characteristics are shown in Table 1. Because our patients visited a university hospital

Table 2 Association Between the Number of Eradication Attempts and lgE Levels

\begin{tabular}{|l|l|l|l|l|}
\hline $\begin{array}{l}\text { Number of } \\
\text { Eradication Attempts }\end{array}$ & $\mathbf{n}$ & $\begin{array}{l}\text { Mean IgE, } \\
\text { IU/mL }\end{array}$ & SD & P-value \\
\hline One & 44 & 188.4 & 244.6 & $\mathbf{0 . 0 0 4}$ \\
Two & 81 & 211.9 & 395.2 & \\
Three or more & 26 & 744.0 & 1612.6 & \\
\hline
\end{tabular}

Note: Bold text, statistically significant at $\mathrm{P}<0.05$

Abbreviation: SD, standard deviation. rather than a general practitioner for eradication, they were considered to be a characteristic group and not a general population group. Most patients were over the age of 61 years. The reported lifestyle habits of the patients included alcohol intake and smoking. About $80 \%$ of the patients had been tested for $H$. pylori and $60 \%$ had been treated for eradication. In addition, $40 \%$ of the patients had undergone eradication treatment more than once. Meanwhile, about $10 \%$ of the patients with autoimmune gastritis had come to the hospital for $H$. pylori eradication but did not actually have $H$. pylori infection.

Table 2 shows the relationship between the number of eradication attempts and $\operatorname{IgE}$ levels using one-way analysis of variance. The mean $\operatorname{IgE}$ values were 188.4, 211.9, and 744.0 IU/mL in patients with one, two, and three or more eradication attempts, respectively $(\mathrm{P}<0.05)$. The overall mean was $296.7 \mathrm{IU} / \mathrm{mL}$, which was higher than the standard value of $173 \mathrm{IU} / \mathrm{mL}$ or less with the FEIA method. ${ }^{12}$

Table 3 shows the association between the number of eradication attempts (with one eradication as reference) and high $\operatorname{IgE}(\geq 500 \mathrm{IU} / \mathrm{mL})$ and low $\operatorname{IgE}(<500 \mathrm{IU} / \mathrm{mL})$ levels using multinomial logistic regression analysis (with low IgE as reference). In all models, there was no significant association between two eradication attempts and high IgE levels, although eradication was slightly more difficult compared with a single eradication. However, in all models, attempting eradication three or more times was significantly associated with high IgE levels.

\section{Discussion}

To our knowledge, this is the first study to examine the relationship between the difficulty of $H$. pylori eradication and the $\operatorname{IgE}$ level. Our results suggest that eradication failure is more common in patients with high $\operatorname{IgE}$ levels and that such patients may require multiple eradication attempts. The patients who visited our university hospital were considered to be resistant to $H$. pylori eradication because they had previously experienced $H$. pylori

Table 3 Association Between the Number of Eradication Attempts and a High IgE Level ( $\geq 500 \mathrm{IU} / \mathrm{mL})$

\begin{tabular}{|l|l|l|l|l|c|c|}
\hline \multirow{2}{*}{} & \multicolumn{3}{|c|}{ Two } & \multicolumn{3}{c|}{ Three or More } \\
\cline { 2 - 7 } & OR & $\mathbf{9 5 \%} \mathbf{C l}$ & P-value & $\mathbf{O R}$ & $\mathbf{9 5 \%} \mathbf{~ C l}$ & P-value \\
\hline Model I & 1.50 & $0.38-5.96$ & 0.566 & $\mathbf{5 . 0 4}$ & $1.17-21.63$ & $\mathbf{0 . 0 3 0}$ \\
Model 2 $^{\mathrm{a}}$ & 1.23 & $0.30-4.99$ & 0.776 & $\mathbf{4 . 5 2}$ & $1.03-19.88$ & $\mathbf{0 . 0 4 6}$ \\
Model 3 $^{\mathrm{b}}$ & 1.27 & $0.30-5.43$ & 0.747 & $\mathbf{5 . 0 3}$ & $1.06-23.86$ & $\mathbf{0 . 0 4 2}$ \\
\hline
\end{tabular}

Notes: $\lg \mathrm{E}<500 \mathrm{IU} / \mathrm{mL}$ and one eradication attempt as reference. ${ }^{\mathrm{a}}$ Model 2 was adjusted for clarithromycin sensitivity. ${ }^{\mathrm{b}}$ Model 3 was adjusted for clarithromycin sensitivity, sex, age, smoking status, and drinking status. Bold text, statistically significant at $\mathrm{P}<0.05$.

Abbreviations: $\mathrm{OR}$, odds ratio; $\mathrm{Cl}$, confidence interval. 
eradication failure at general practitioners or in private hospitals or had adverse effects from eradication drugs. If there is an attribute of patients that hinders $H$. pylori eradication, it may be related to their high IgE levels.

Several previous studies have reported an association between allergic diseases and $H$. pylori. For instance, inverse associations of $H$. pylori with allergic rhinitis ${ }^{13}$ and asthma ${ }^{14}$ have been reported. Another earlier study mentioned that $H$. pylori neutrophil-activating protein could be an important candidate for novel strategies in the prevention and treatment of asthma and allergic diseases. $^{15,16}$

We considered IgE levels above $500 \mathrm{IU} / \mathrm{mL}$ to be high. We used this threshold because several previous studies have used $\mathrm{IgE}$ levels of $500 \mathrm{IU} / \mathrm{mL}$ or higher as high or reference values. ${ }^{17-20}$

In the present study, patients with higher IgE levels were more frequently treated for $H$. pylori eradication (Table 2). This suggests that people who have difficulty eradicating $H$. pylori may show a tendency for high $\operatorname{IgE}$ levels. However, because susceptibility to clarithromycin was not considered, we further analyzed the results by taking susceptibility into account, given that many Japanese are resistant to clarithromycin. ${ }^{21}$

As shown in Table 3, we used multinomial logistic regression because the dependent variable was divided into three levels: one, two, and three or more eradication attempts. Model 1 is the crude model. Model 2 in Table 3 shows the results of the analysis with the addition of clarithromycin sensitivity. In model 3, susceptibility, sex, age, alcohol consumption, and smoking status were added as covariates. The results showed that high IgE levels were associated with a high number of eradication attempts, even when antimicrobial susceptibility was taken into account. These findings thus suggest that $\operatorname{IgE}$ influences eradication difficulty.

According to previous research, an increase in IgEcontaining plasma cells results in various non-specific chronic inflammatory disorders of the upper gastrointestinal tract. ${ }^{22}$ In addition, the number of IgE-positive cells is significantly elevated in patients with chronic gastritis compared with normal mucosa and is accompanied by a significant accumulation of IgE-positive plasma cells in patients with $H$. pylori-positive gastritis, suggesting that IgE-mediated immune responses play an important role in the development of $H$. pylori-associated gastritis. $^{23,24}$ Furthermore, prolonged $H$. pylori infection has been reported to promote the production of specific $\mathrm{IgE}$ antibodies. ${ }^{25}$ These findings suggest that IgE is closely related to $H$. pylori infection and that patients with longterm H. pylori infection may have high IgE levels. This may lead to the difficult eradication.

A study related to allergy showed that when an H. pylori-infected stomach is ulcerated, the regulatory $\mathrm{T}$ cell response is insufficient. Although this is a hypothesis, regulatory $\mathrm{T}$ cell-mediated suppression of inflammation and the bactericidal activity of epithelial cells may influence the increase in $H$. pylori density and the maintenance of prolonged bacterial colonization. ${ }^{26}$ In this context, allergic individuals may have an imbalance in regulatory $\mathrm{T}$ cells, which may be an unstable factor that exacerbates the pathogenesis of $H$. pylori infection. A decrease in regulatory $\mathrm{T}$ cells causes downregulation of adaptive immunity and promotes persistence of H. pylori infection. ${ }^{27}$ Regulatory $\mathrm{T}$ cells suppress $\mathrm{T} 2$ cells to prevent allergies but IgE production increases when this suppression is no longer effective and cytokines released by $\mathrm{T} 2$ cells stimulate $\mathrm{B}$ cells. In view of the above hypothesis, people with high IgE levels may have a higher density of $H$. pylori and prolonged bacterial colonization. A previous study examining the relationship between the eradication rate of $H$. pylori and H. pylori density found that the higher the bacterial density of $H$. pylori, the significantly more difficult its eradication. ${ }^{28}$

There are four main limitations to this study. First, the frequency of eradication was self-reported by the patients; however, patients have to take many types and doses of eradication medicines for a week and it is unlikely that they mistook how many times they took the eradication medication. Second, as mentioned above, the target population is biased because it consisted of patients who visited a university hospital. However, because the patients were from a university hospital, we were able to conduct a survey of individuals who had undergone multiple eradication attempts, which is rarely seen in patients who generally visit clinics. Third, we do not know the patients' adherence to the medication. However, we believe that because the patients had already undergone more than one eradication attempt, they had a strong desire to achieve eradication, which should lead to good adherence. Fourth, we were not able to measure specific $\operatorname{IgE}$ in this study. Further studies are needed to investigate allergic factors in more detail.

The eradication rate of $H$. pylori has increased dramatically since the prescription of eradication drugs was changed in 2015. However, despite the increased 
eradication success rate, $H$. pylori eradication may still be difficult in some people, which may be due to patient factors. Factors that might contribute to $H$. pylori eradication failure in patients with high IgE levels include longterm infection, because prolonged $H$. pylori infection promotes the production of specific IgE antibodies, and increased $H$. pylori density, which makes bacteria eradication more difficult.

In this study, we found that patients with high $\operatorname{IgE}$ levels were less likely to achieve $H$. pylori eradication, suggesting that individuals with high $\operatorname{IgE}$ should be more cautious when taking $H$. pylori eradication medication because they may have a constitution that hampers its eradication. In addition, the appropriate regimen for patients with high IgE levels should be studied.

\section{Conclusion}

Our analysis shows that, even after consideration of antibiotic sensitivity, patients with high $\operatorname{IgE}$ levels are less likely to eradicate $H$. pylori. Therefore, patients with high IgE need to be more cautious when taking $H$. pylori eradication drugs. IgE is closely related to $H$. pylori infection and patients with long-term $H$. pylori infection may have high IgE levels.

\section{Abbreviations}

H. pylori, Helicobacter pylori; IgE, immunoglobulin E.

\section{Ethics}

This study was approved by the Clinical Research Ethics Committee of Hamamatsu University School of Medicine (No. 17-072). The study complied with the Declaration of Helsinki.

\section{Acknowledgments}

We thank the management and staff of the Department of Gastroenterology of Hamamatsu University School of Medicine and the patients who provided the data for this study.

\section{Funding}

This work was supported by JSPS KAKENHI Grant Number JP 17K09105. The funding source played no role in study design, in the collection, analysis or interpretation of data, in the writing of the report, or in the decision to submit this manuscript for publication.

\section{Disclosure}

Mrs Kayoko Ozeki reports grants, personal fees from the Japan Society for the Promotion of Science (JSPS), during the conduct of the study. The authors report no other conflicts of interest associated with this work.

\section{References}

1. Watanabe T, Tada M, Nagai H, Sasaki S, Nakao M. Helicobacter pylori infection induces gastric cancer in mongolian gerbils. Gastroenterology. 1998;115(3):642-648. doi:10.1016/S00165085(98)70143-X

2. Forman D. The EUROGAST Study Group. An international association between Helicobacter pylori infection and gastric cancer. Lancet. 1993;341(8857):1359-1362. doi:10.1016/0140-6736(93)90938-D

3. Uemura N, Okamoto S, Yamamoto S, et al. Helicobacter pylori infection and the development of gastric cancer. $N$ Engl $J$ Med. 2001;345(11):784-789. doi:10.1056/NEJMoa001999

4. Forman D, Newell DG, Fullerton F, et al. Association between infection with Helicobacter pylori and risk of gastric cancer: evidence from a prospective investigation. BMJ. 1991;302 (6788):1302-1305. doi:10.1136/bmj.302.6788.1302

5. Wong BC, Lam SK, Wong WM, et al. Helicobacter pylori eradication to prevent gastric cancer in a high-risk region of China: a randomized controlled trial. JAMA. 2004;291(2):187-194. doi:10.1001/jama.291.2.187

6. Uemura N, Mukai T, Okamoto S, et al. Effect of Helicobacter pylori eradication on subsequent development of cancer after endoscopic resection of early gastric cancer. Cancer Epidemiol Biomarkers Prev. 1997;6(8):639-642.

7. Sasaki H, Nagahara A, Hojo M, et al. Ten-year trend of the cumulative Helicobacter pylori eradication rate for the 'Japanese eradication strategy'. Digestion. 2013;88(4):272-278. doi:10.1159/000353313

8. Sasaki M, Ogasawara N, Utsumi K, et al. Changes in 12-year first-line eradication rate of Helicobacter pylori based on triple therapy with proton pump inhibitor, amoxicillin and clarithromycin. J Clin Biochem Nutr. 2010;47(1):53-58. doi:10.3164/jcbn.10-10

9. Lyu QJ, Pu QH, Zhong XF, Zhang J. Efficacy and safety of vonoprazan-based versus proton pump inhibitor-based triple therapy for Helicobacter pylori eradication: a meta-analysis of randomized clinical trials. Biomed Res Int. 2019;2019:9781212. doi:10.1155/ 2019/9781212

10. Ozeki K, Furuta T, Asano M, et al. Association of hay fever with the failure of Helicobacter pylori primary eradication. Intern Med. 2016;55(13):1729-1734. doi:10.2169/internalmedicine.55.6388

11. Ozeki K, Asano M, Furuta T, Ojima T. Relationship between primary eradication of Helicobacter pylori and drinking habits in women: collaborative research between a pharmacy and a clinic. Epidemiol Infect. 2019;147:e292. doi:10.1017/S0950268819001730

12. Shimazu S, Enomoto T. Serum IgE levels in healthy children. Jpn J Allergol Immunol. 1995;2(7):62-67.

13. Chen Y, Blaser MJ. Inverse associations of Helicobacter pylori with asthma and allergy. Arch Intern Med. 2007;167:821-827. doi:10.1001/archinte.167.8.821

14. Imamura S, Sugimoto M, Kanemasa K, et al. Inverse association between Helicobacter pylori infection and allergic rhinitis in young Japanese. J Gastroenterol Hepatol. 2010;25:1244-1249. doi:10.1111/ j.1440-1746.2010.06307.x

15. Amedei A, Codolo G, Del Prete G, et al. The effect of Helicobacter pylori on asthma and allergy. J Asthma Allergy. 2010;3:139-147.

16. Karakullukcu A, Tokman HB, Nepesov S, et al. The protective role of Helicobacter pylori neutrophil-activating protein in childhood asthma. Allergol Immunopathol. 2017;45(6):521-527. doi:10.1016/j. aller.2017.01.008 
17. Grabenhenrich L, Lange L, Härtl $\mathrm{M}$, et al. The component-specific to total $\mathrm{IgE}$ ratios do not improve peanut and hazelnut allergy diagnoses. $J$ Allergy Clin Immunol. 2016;137(6):1751-1760. doi:10.1016/j. jaci.2016.01.043

18. Lin IH, Tsai MC, Chen JP, Fu LS. Allergic children with extremely high total IgE but no allergen identified in the initial screening panel. J Microbiol Immunol Infect. 2020. doi:10.1016/j.jmii.2020.01.001

19. Beeh KM, Ksoll M, Buhl R. Elevation of total serum immunoglobulin $\mathrm{E}$ is associated with asthma in nonallergic individuals. Eur Respir J. 2000;16(4):609-614. doi:10.1034/j.1399-3003.2000.16d07.x

20. Nepomuceno IB, Esrig S, Moss RB. Allergic bronchopulmonary aspergillosis in cystic fibrosis: role of atopy and response to itraconazole. Chest. 1999;115(2):364-370. doi:10.1378/chest.115.2.364

21. Horie R, Handa O, Ando T, et al. Helicobacter pylori eradication therapy outcome according to clarithromycin susceptibility testing in Japan. Helicobacter. 2020;25(4):e12698. doi:10.1111/hel.12698

22. van Spreeuwel JP, Lindeman J, van Maanen J, Meyer CJ. Increased numbers of $\operatorname{IgE}$ containing cells in gastric and duodenal biopsies. An expression of food allergy secondary to chronic inflammation? J Clin Pathol. 1984;37(6):601-606. doi:10.1136/jcp.37.6.601

23. Berczi L, Sebestyén A, Fekete B, Tamássy K, Kopper L. IgEcontaining cells in gastric mucosa with and without Helicobacter pylori infection. Pathol Res Pract. 2000;196(12):831-834. doi:10.1016/S0344-0338(00)80083-7
24. Aceti A, Celestino D, Caferro M, et al. Basophil-bound and serum immunoglobulin E directed against Helicobacter pylori in patients with chronic gastritis. Gastroenterology. 1991;101(1):131-137. doi:10.1016/0016-5085(91)90469-2

25. Kurbel S, Kurbel B. The role of gastric mast cells, enterochromaffin-like cells and parietal cells in the regulation of acid secretion. Med Hypotheses. 1995;45(6):539-542. doi:10.1016/ 0306-9877(95)90236-8

26. Robinson K, Kenefeck R, Pidgeon EL, et al. Helicobacter pylori-induced peptic ulcer disease is associated with inadequate regulatory $\mathrm{T}$ cell responses. Gut. 2008;57(10):1375-1385. doi:10.1136/gut.2007.137539

27. Romero-Adriàn TB, Leal-Montiel J. Helicobacter pylori infection: regulatory $\mathrm{T}$ cells and their participation in the immune response. Jundishapur J Microbiol. 2013;6(4). doi:10.5812/jjm.5183

28. Moshkowitz M, Konikoff FM, Peled Y, et al. High Helicobacter pylori numbers are associated with low eradication rate after triple therapy. Gut. 1995;36(6):845-847. doi:10.1136/gut.36.6.845
Clinical and Experimental Gastroenterology

\section{Publish your work in this journal}

Clinical and Experimental Gastroenterology is an international, peerreviewed, open access, online journal publishing original research, reports, editorials, reviews and commentaries on all aspects of gastroenterology in the clinic and laboratory. This journal is indexed on American Chemical Society's Chemical Abstracts Service (CAS).

\section{Dovepress}

The manuscript management system is completely online and includes a very quick and fair peer-review system, which is all easy to use. Visit http://www.dovepress.com/testimonials.php to read real quotes from published authors. 